\title{
15. Implementing Gateway in the Australian Government
}

\author{
Department of Finance and Administration, Australian \\ Government ${ }^{1}$
}

\section{Introduction}

This chapter examines the Australian Government's approach and experience to date in implementing the Gateway Review Process (Gateway).

The Australian Government undertook research in 2005 to identify ways to improve the delivery of major projects (as measured by successful project delivery on time and within budget) by Financial Management and Accountability Act 1997 agencies (FMA agencies). From the options available to the Government for meeting this objective, the decision was made by Cabinet to implement Gateway, which had been developed in the United Kingdom by the Office of Government Commerce in 2000 and subsequently applied by the Victorian Government in 2003.

Gateway is a project assurance methodology designed to improve project delivery. The methodology involves a small team of independent experts conducting short, intensive and timely reviews at key decision points (referred to as Gates) during the life of the project. The reviews focus on the issues that are most important to the project at that stage of the project's life, with reference to an established set of areas to be considered for each Gate that address the proven and comprehensive Gateway methodology. One of the key benefits of Gateway is that the reviews are focussed and short in duration, allowing reports to be high level and action oriented, highlighting where corrective action may be required at that particular point in time.

Implementation of Gateway provides an opportunity for the Australian Government to apply an approach that is acknowledged to have delivered on its objectives. ${ }^{2}$ Demonstrable benefits in respect to project delivery have been achieved in other jurisdictions through:

- identifying the skills and experience required to deliver successful projects;

- increasing stakeholder understanding of their role in successful project management and the factors which contribute to the achievement of project objectives;

- identifying early in projects where corrective action may be required; and

- improving project management and delivery skills. 
Gateway also sits well with the Government's budgeting and accountability framework. ${ }^{3}$

\section{The Phasing-in of Gateway}

Drawing on the experience of other jurisdictions, the Australian Government decided to phase in the implementation of Gateway over three budget cycles to allow time to consider the nuances of Gateway and adapt it where appropriate. In taking this approach, FMA agencies have the time, support, and opportunity to be fully engaged in the establishment of Gateway in the Australian Government, thereby helping to realise the benefits of Gateway.

A particular benefit of this phased approach has been having the time to develop an Australian Government focused Gateway training program and to train suitable Australian Public Service (APS) staff and private sector personnel as Gateway reviewers. One of the main outcomes sought in introducing Gateway into the Australian Government was to share and improve upon the project management skills of the APS. The involvement of public servants as reviewers capitalises on this existing expertise and facilitates the development and dissemination of project management and other skills across the APS.

\section{The Implementers}

At the direction of the Government, the Gateway Unit was established within the Department of Finance and Administration (Finance) to manage the introduction and continued operation of Gateway. The Gateway Unit:

- $\quad$ provides guidance and advice to agencies and reviewers;

- coordinates gateway reviews, including the selection and assembly of gateway review teams and assisting with logistical and administrative arrangements;

- disseminates generic lessons learnt on the management of major projects throughout the APS; and

- verifies gateway assessment tool (GAT) indicative risk ratings for projects prior to cabinet consideration of the proposal.

Although the Gateway Unit coordinates reviews, they do not participate as reviewers, nor are they responsible for actions taken by agencies on Gateway Review Report recommendations. The Unit takes the confidentiality of Gateway very seriously and as such does not disclose project information provided to the Unit, even to other areas of Finance.

To assist participants in the efficient and effective conduct of Gateway reviews, the Gateway Unit has developed publications as part of Finance's Financial Management Guidance (FMG) and Reference (FMR) series. The publications are:

- FMG No. 20, Guidance on the Gateway Review Process - A Project Assurance Methodology for the Australian Government (the Guidance); and 
- $\quad$ FMR No. 7, Gateway Review Process - A Handbook for Conducting Gateway Reviews (the Handbook).

A high level Brochure on Gateway is also available. It provides a high level overview of gateway for those wanting to gain a general understanding of the Gateway Review Process.

The purpose of the Guidance is to provide an introduction and practical information to Gateway reviewers, project teams and other potential participants on the process and requirements of Gateway.

The Handbook complements the Guidance and is intended to be a resource document to assist with the successful preparation for, conduct of, and participation in, Gateway reviews. It includes material on:

- the purpose of the review for each specific Gate;

- a list of the likely project documents to be reviewed at each Gate;

- areas to probe and the evidence required at each Gate, including possible questions; and

- a Gateway Review Report template.

As each project is different, the Handbook is not an exhaustive reference. It provides information that will assist with promoting a consistency of approach for conducting reviews of different projects across government and should be used to complement the expertise of the Gateway review team.

The Gateway Guidance, Handbook and Brochure are all available at the Gateway website, at www.finance.gov.au/gateway. The website also contains advice on the Gateway reviewer training, the application process to become a Gateway reviewer, the GAT (discussed later in this chapter) and a Frequently Asked Questions section for potential reviewers.

\section{The Review Points}

The Gateway Review Process is tied to the key decision points (referred to as Gates) of a project's lifecycle. The Australian Government's implementation of Gateway closely models the United Kingdom's (UK) application of the process; however, there has been some alteration of the content focus of each Gate to accommodate the Australian Government working environment, policy and processes. The Gates are illustrated in the diagram on the following page: 


\section{Figure 1}

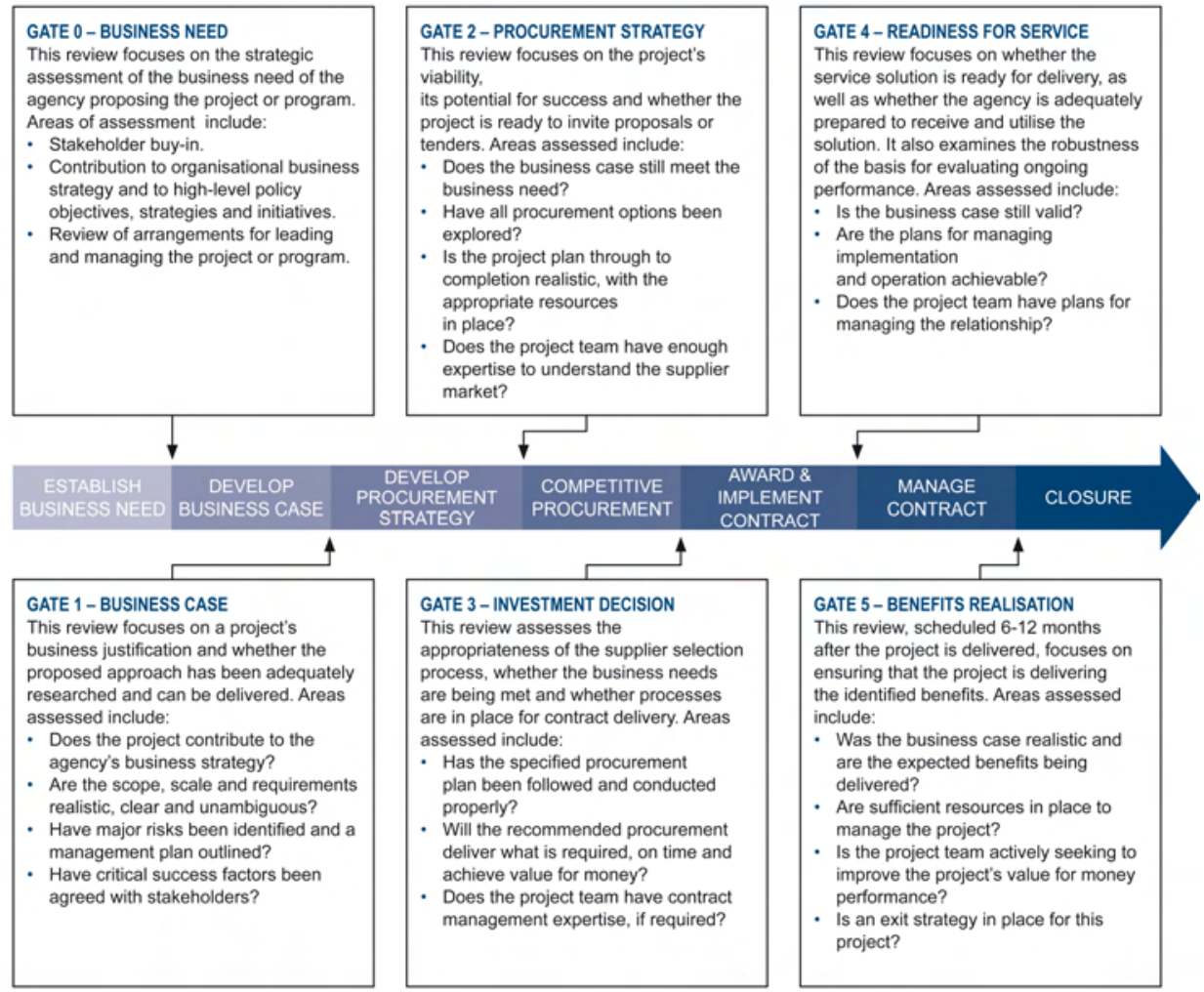

\section{The Thresholds}

Not all Australian Government projects will undertake Gateway. Gateway only applies to new projects conducted by FMA agencies, which satisfy certain financial and risk thresholds and which are being submitted to Cabinet for approval.

The current financial thresholds are:

- $\quad \$ 10 \mathrm{M}$ and above for Information Technology (IT) projects; and

- $\$ 20 \mathrm{M}$ and above for other procurement and infrastructure projects

These costs are calculated over the life of the project (not just in one financial year) and include capital and operating expenses. These different financial thresholds were set based on the research and experience of FMA agencies, which established that there is generally a higher risk for IT projects than for other projects. The financial thresholds will be reviewed from time to time to ensure their appropriateness.

The second criterion, risk, is determined using the GAT. FMA agencies seeking Cabinet approval for projects costed in excess of the financial thresholds are 
required to submit a completed GAT to the Gateway Unit before the consideration of the project by Cabinet.

The GAT is a high level assessment tool that is designed to identify the indicative level of risk for a project. It provides a set of criteria against which an agency can assess the characteristics and degree of complexity of a proposed project, in order to develop an overall indicative risk rating. The risk rating is then confirmed in discussions with the Gateway Unit. The questions in the GAT allow for the provision of a written explanation for each of the responses to help inform the Gateway Unit in assessing the overall project risk.

As part of the phased implementation of Gateway, during the 2006-07 Budget process projects meeting the financial thresholds were required to complete the GAT. The Prime Minister and the Minister for Finance and Administration subsequently agreed to five projects undertaking Gateway. These five projects represent a cross section of projects of differing financial values and from both the ICT and infrastructure classifications.

Since May 2006, all projects meeting the financial thresholds and assessed as high risk are required to undertake the Gateway Review Process, if the project is approved by Cabinet. All projects assessed as high risk must have their Gate 1 Business Case Review scheduled prior to Cabinet considering the proposal. Commencing with the 2008-09 Budget process the risk threshold will be extended to include medium risk as well as high risk projects.

A subset of high risk projects have been defined by the Government as 'Mission Critical', and as such, the Government has decided that additional governance requirements be applied to these projects, on the basis that:

- $\quad$ such projects are essential to the successful delivery of a major legislative requirement or a major policy initiative committed to by the Government; or

- project failure would have catastrophic implications for delivery of a key public service, national security or the internal operation of an agency.

The classification of projects as 'Mission Critical' is expected to be rare.

\section{The Reviews}

A Gateway review is a highly interactive, cooperative and confidential process involving the Gateway review team, the Senior Responsible Official (SRO) ${ }^{4}$ and the Sponsoring Agency's Project Team. It is neither an audit nor intended to be onerous for the Sponsoring Agency. The project can continue while the review is being conducted and the review should not require new documentation to be produced; it focuses on information already developed.

Gateway reviews are conducted by independent reviewers - people not associated with the project itself. Gateway reviewers are sourced from the public and 
private sectors and are selected for their skills and experience, not to represent their agency or firm. For high risk projects, the selection, engagement and funding of the review team is by Finance. For medium risk projects, the Review Team Leader will be selected, engaged and funded by Finance, but the remaining Team members (usually three) will be staff nominated from within the Sponsoring Agency who are not associated with the project.

As part of a Gateway review, the review team is provided access to relevant project documentation and to the stakeholders involved with and / or affected by the project. Stakeholders are encouraged to be as frank as possible in their discussions with the review team during the review in order to help the team gain an understanding of key issues or concerns.

There are three key stages in a Gateway review:

1. An Assessment Meeting between the Gateway Unit and the SRO and Project Manager for the project, to clarify the characteristics of the project, discuss the timing and logistics of the review and determine the skills requirements for potential reviewers. This meeting will generally take one hour.

2. A Planning Meeting between the assigned Gateway review team and the significant project personnel (including the SRO and the Project Manager) to clarify the project's characteristics and the requirements for the review. Requirements include the documentation to be provided, people to be interviewed and logistics associated with the review. This meeting will generally take no more than half a day.

3. The Onsite Review Activity, which involves examination of critical documentation and interviews with key Project Team members and other project stakeholders on the Sponsoring Agency's premises. Interviews will be carefully planned and scheduled to minimise the disruption to interviewees. The Onsite Review Activity typically takes four to five working days to complete. The Review Team Leader will brief the SRO on a daily basis regarding any findings to date. This briefing typically takes less than half an hour.

Gateway reviews should take approximately six weeks to complete from the Assessment Meeting to the conclusion of the Onsite Review Activity. To maximise the benefit attained from a Gateway review, the review activity should ideally take place four to six weeks prior to a major decision point to allow time to consider and implement recommendations emanating from the review.

Each Gateway review produces a short confidential report, which is provided to the Sponsoring Agency's SRO. To enable the review team to produce a report which is of most use to the Sponsoring Agency, there needs to be a willingness by all parties to share information openly and honestly. The Gateway Unit works to ensure this through: 
- careful selection of review teams;

- ongoing liaison with review teams and FMA agencies;

- communication and dissemination of guidance material;

- ongoing training for the Gateway Review Process; and

- $\quad$ supporting the confidentiality of the process.

Communication with Sponsoring Agencies in the implementation of Gateway is a key focus for the Gateway Unit. That is why communication commences as early as possible in preparation for a review and continues through to the conclusion of the review. There will be a great deal of interaction between the Gateway Unit, the review teams and the FMA agencies participating in reviews.

Proactive involvement of the SRO is an essential element in a Gateway review. The SRO is important because they:

- oversee preparations for a review and take responsibility for meeting the agency's obligations;

- $\quad$ are the focal point for the work undertaken by a review team;

- own the review report and control its distribution;

- decide what, if any, action should be taken in response to the review team's recommendations; and

- $\quad$ are in a position to influence the people associated with the project, to help lay the foundation for a productive interaction with the gateway review team.

The focus of the review team's work is to provide a useful report to the SRO through the findings and recommendations they develop. Although they are providing a report to the SRO, the independence of the review is crucial to the success of Gateway. The review team is not working for the SRO, and the SRO can not dictate the way the review is conducted or what goes in to the report.

\section{Gateway Reports}

The product of a Gateway review is a Gateway Review Report which is handed over to the SRO on the last day of the Onsite Review Activity. Review reports are confidential, high level and action-oriented and around eight to ten pages in length. They are prepared for the Sponsoring Agency, not for the Gateway Unit. Because the review team meet daily with the SRO and a draft of the report is usually provided on the second last day of the review. The content and findings of the report should not be a surprise to the SRO but rather a summation of the advice and discussions that have been held during the review activity. Regardless of how critical its recommendations are, the Gateway report itself does not stop a project. It is the SRO's responsibility to decide the appropriate action to address the Gateway review findings. 
The overall status for a Gateway reviewed project is indicated by a 'colour code' system of red, amber and green which allows the SRO to quickly determine how critical the recommendations are. It is emphasised to Sponsoring Agencies that a red rating does not indicate a project should stop; rather, it is critical to the success of the project that the issues raised in the report are addressed. An amber rating indicates that the issues raised in the report should be addressed before the next Gateway review. A green rating indicates that the project is on target, but may benefit from implementing the recommendations in respect to the issues raised in the review.

As part of the Gateway Unit is broader policy work in ensuring lessons learnt in projects are shared across the APS, a summary of the review recommendations are provided to the Unit at the end of the review for collation on a non-attributable basis. As part of this lessons learnt activity the Unit also receives a full copy of the Gateway Review Report but only once the next Gate is completed and in the case of the final gate review (Gate 5 - Benefits Realisation), the report is received three months following the review. The Unit does not receive a copy of the report to follow up what action was taken with respect to the recommendations, it is only for the purposes of developing the lessons learnt policy advice and to ensure the quality of reports is of an acceptable and consistent standard across reviews.

\section{The Opportunities}

In introducing Gateway to Australian Government projects, the Gateway Unit has been able to leverage off the experience of previous implementations of the Gateway Review Process in the UK and in Victoria, Australia. The Gateway Unit would like to acknowledge the considerable assistance both the Office of Government Commerce in the UK and the Gateway Unit of the Department of Treasury and Finance in Victoria have given Finance in establishing Gateway in the Australian Government.

The objective of Gateway for the Australian Government is to improve the delivery of major projects; however, Gateway does present other opportunities for the Government. The benefits of Gateway, effectively implemented, are expected to extend beyond the projects passing through Gateway so that learning and the dissemination of experience from the reviews can assist the development of improved project management across the APS.

\section{References}

Australian Public Service Commission 2004, Connecting Government: Whole of Government Responses to Australia's Priority Challenges, APSC, Canberra, available at www.apsc.gov.au/mac/connectinggovernment.pdf 
National Audit Office Report (HC 877, 2003-2004): Improving IT procurement: The impact of the Office of Government Commerce's initiatives on departments and suppliers in the delivery of major IT-enabled projects, UK NAO, London, available at http://www.nao.org.uk/publications/nao_reports/03-04/0304877.pdf

\section{ENDNOTES}

1 This chapter is an updated and expanded version of a presentation delivered at the conference by Robert Higgins, (then) Branch Manager of the Gateway Unit in the Department of Finance and Administration.

2 National Audit Office Report (HC 877, 2003-2004): Improving IT procurement: The impact of the Office of Government Commerce's initiatives on departments and suppliers in the delivery of major IT-enabled projects.

3 Australian Public Service Commission 2004, Connecting Government: Whole of Government Responses to Australia's Priority Challenges - Chapter 5.

4 The Senior Responsible Official (SRO) is the official within the Sponsoring Agency that has overall accountability for the realisation of the project outcomes and objectives for the project under review. 